Tohoku J. Exp. Med., 1995, 177, 89-92

Short Report

\title{
The Secular Trend in the Incidence of Subarachnoid Hemorrhage in Miyagi, Japan: 1979-1990
}

\author{
Yoshiaki Sakurai, Jing-hua Li*, Shoko Komatsu $\dagger$, \\ Hiroshi Saito $\ddagger$, Suesaburo Abe§, Akiyuki Yamada //, \\ Mitsuaki Nishikori $\emptyset$, Ichiro Tsuji* and Shigeru \\ HisAMICHI* \\ Stroke Center of Sendai National Hospital, Sendai 983, \\ *Department of Public Health, Tohoku University School \\ of Medicine, Sendai 980-77, †Public Health Division, \\ Faculty of Physical Education, Sendai College, Miyagi \\ 989-16, \$Department of Neurology, Tohoku University \\ School of Medicine, Sendai 980-77, §Abe Medical Clinic, \\ Sendai 980, // Tohoku Kosai Hospital, Sendai 980, and \\ ๆ Department of Health and Welfare, Miyagi Prefectural \\ Office, Sendai 980
}

Sakurai, Y., Li, J., Komatsu, S., Saito, H., Abe, S., Yamada, A., Nishikori, M., Tsuji, I. and Hisamichi, S. The Secular Trend in the Incidence of Subarachnoid Hemorrhage in Miyagi, Japan: 1979-1990. Tohoku J. Exp. Med., 1995, 177 (1), 89-92 - Since 1978, a stroke registry has been carried out in Miyagi Prefecture (2.2 million in population), Japan. Approximately 2,000 cases of stroke were annually registered through 16 hospitals which have cerebrovascular disease units. The incidence of subarachnoid hemorrhage was 17.4 per 100,000 population in 1990. The incidence increased gradually during early 1980's and reached plateau during late 1980's. Furthere, the trend in the incidence of subarachnoid hemorrhage is compared with those in other communities in other countries as well as Japan. _ Japan; epidemiology; subarachnoid hemorrhage; incidence; registry

The Miyagi Prefecture Stroke Registry, established in 1978 by the Miyagi Stroke Society, is based on patients registration from 16 hospitals which have cerebrovascular diseases (CVD) units. In 1990, a total of 2215 cases were registered. Those includes cerebral infarction (875 cases, $40 \%$ ), intracerebral hemorrhage (542 cases, $25 \%$ ), subarachnoid hemorrhage ( $\mathrm{SAH}$ ) (391 cases, 18\%), and chronic subdural hematoma (134 cases, $6 \%$ ). In registered cases, data for SAH are the most suitable for epidemiological study, since almost all SAH cases are sent from primary care clinics to one of above 16 hospitals for evaluation and treatment. In contrast, the other cerebrovascular diseases may not be

Received April 7, 1995; revision accepted for publication July 20, 1995.

Address for reprints: Dr. Yoshiaki Sakurai, Stroke Center of Sendai National Hospital, 2-8-8 Miyagino, Miyagino-ku, Sendai 983, Japan. 
suitable for epidemiological study, since the patients are sometimes treated in local hospitals. In this study, the trend in the incidence of SAH is compared with those in other communities, both in- and outside of Japan.

The investigation included all of SAH patients who were registered in Miyagi Prefecture. Stroke Registry between 1979 and 1990. In all cases, diagnosis were made with CT, and cerebral angiography were underwent in $90 \%$ of cases. Information in the stroke registry includes; personal identifiers (name, date of birth), date of onset, symptoms, disturbance of consciousness (Japan Coma Scale), activities of daily living (ADL), status one month after stroke, therapy, and past medical history. Among these data, we focused on the incidence of SAH in this study. The age-specific rates were calculated and compared with those in other communities. For appropriate comparisons in the incidence of SAH, age-adjusted incidence was standardized with European age-related population distribution (World Health Organization 1994), in communities where age-specific rates were available.

Fig. 1 shows the trend in age-adjusted incidence of SAH in Miyagi from 1979 to 1990. The incidence increased gradually during early 1980's and reached plateau during late 1980's. The total registered number of SAH were 286 in 1980, 406 in 1985, and 391 in 1990, respectively. Table 1 shows the number, age-specific rate, crude and age-adjusted incidence in Miyagi in 1990. The female/male ratio of SAH in 1990 was approximately 1.8 (252/ 139). The age-specific rates for males gradually increased 40-49 to 60-69 years old groups, then declined. The rates for females increased from $40-49$ to $70-79$ years old groups, then declined. The age-adjusted incidences for males were 0.15 in 1980, 0.17 in 1985, and 0.13 in 1990. The corresponding incidences for females were $0.15,0.22$, and 0.22 . As for the prognosis, five percent of the patients died soon after the onset, and other two percent died within one month after the onset of stroke.

The results of the inter-community comparisons are shown in Table 2. In comparisons with communities where the age-specific rates were available, the age-adjusted incidence in Miyagi was lower than that in Izumo, Japan (1980-1984) (Inagawa et al. 1988), and higher than that in Dijon, France (1985-1989) (Giroud et al. 1991). In comparisons with the other communities where the age-specific rates were not available, i. e., Malmö Sweden (Jerntorp and Berglund 1992) and Frederiksberg, Denmark (Jøgenson et al. 1992), the incidence in these communities were apparently lower than that in Miyagi. In Japan, the age-specific rates in Miyagi was similar to that in Shibata (Tanaka et al. 1981), and much lower than

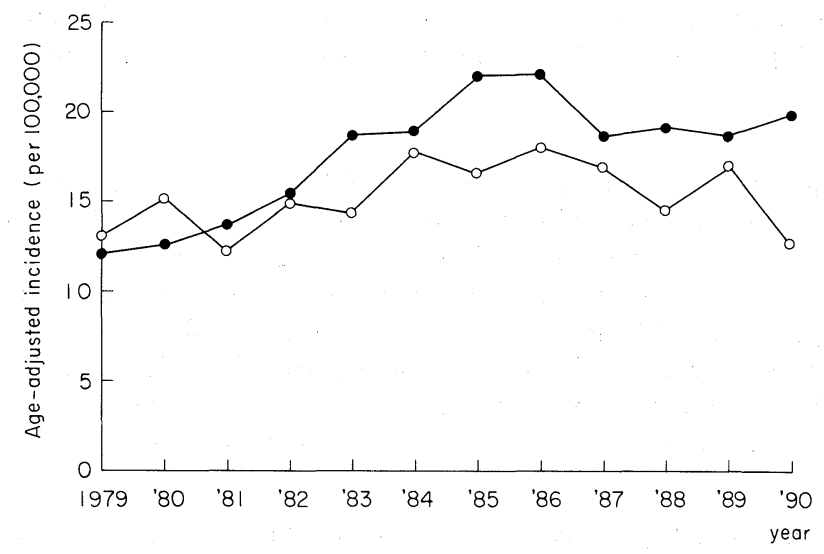

Fig. 1. Trend of incidence of subarachnoid hemorrhage in Miyagi, Japan. (Ageadjusted by European population)

- - male; ○-O female. 
TABLE 1. Incidence (per 100,000 population) of subarachnoid hemorrhage in Miyagi, Japan 1990

\begin{tabular}{|c|c|c|c|}
\hline $\begin{array}{c}\text { Age } \\
\text { (years) }\end{array}$ & Male & Female & Total \\
\hline $0-9$ & $0.0(0)$ & $0.0(0)$ & $0.0(0)$ \\
\hline $10-19$ & $0.0(0)$ & $0.0(0)$ & $0.0(0)$ \\
\hline $20-29$ & $1.3(2)$ & $0.0(0)$ & $0.7(2)$ \\
\hline $30-39$ & $8.0(13)$ & $7.4(12)$ & $7.7(25)$ \\
\hline $40-49$ & $24.2(40)$ & $19.7(32)$ & $22.0(72)$ \\
\hline $50-59$ & $24.7(33)$ & $38.9(56)$ & $32.1(89)$ \\
\hline $60-69$ & $33.0(34)$ & $70.7(86)$ & $53.4(120)$ \\
\hline $70-79$ & $32.3(16)$ & $76.5(55)$ & $58.5(71)$ \\
\hline $80-$ & $5.8(1)$ & $35.1(11)$ & $24.7(12)$ \\
\hline Crude incidence & $12.6(139)$ & $22.1(252)$ & $17.4(391)$ \\
\hline Age-adjusted incidence & $12.6(139)$ & $19.7(252)$ & $16.6(391)$ \\
\hline
\end{tabular}

TABLE 2. Comparison of age-specific and age-adjusted annual incidence of subarachnoid hemorrhage

\begin{tabular}{|c|c|c|c|c|c|c|c|c|c|c|c|}
\hline \multirow[b]{2}{*}{ Study } & \multirow[b]{2}{*}{ Period } & \multicolumn{10}{|c|}{ Age group (years) } \\
\hline & & $0-9$ & $\begin{array}{c}10- \\
19\end{array}$ & $\begin{array}{c}20- \\
29\end{array}$ & $\begin{array}{c}30- \\
39\end{array}$ & $\begin{array}{c}40- \\
49\end{array}$ & $\begin{array}{l}50- \\
59\end{array}$ & $\begin{array}{c}60- \\
69\end{array}$ & $\begin{array}{c}70- \\
79\end{array}$ & $80+$ & $\begin{array}{c}\text { Age- } \\
\text { adjusted }\end{array}$ \\
\hline Hisayama, Japan ${ }^{1)}$ & $1961-83$ & - & - & - & - & 34.9 & 38.4 & 97.4 & 148.9 & 281.7 & - \\
\hline Shibata, Japan²) & $1976-78$ & - & - & 0 & 7.0 & 23.0 & 38.0 & 56.0 & 0 & 0 & - \\
\hline Izumo, Japan ${ }^{3)}$ & $1980-84$ & 0.0 & 0.0 & 4.1 & 6.5 & 21.0 & 61.9 & 59.0 & 51.0 & 33.3 & 21.0 \\
\hline Dijon, France ${ }^{4)}$ & $1985-89$ & 0.0 & 0.0 & 3.7 & 9.0 & 24.0 & 26.1 & 9.3 & 20.0 & 39.4 & 11.2 \\
\hline Malmö, Sweden ${ }^{5), *}$ & 1989 & & & & 2 & 15 & 11 & 0 & 22 & 19 & - \\
\hline $\begin{array}{l}\text { Frederiksberg, } \\
\text { Denmark }^{6),}\end{array}$ & $1989-90$ & & & & & & 2 & 0 & 10 & 0 & - \\
\hline Miyagi, Japan & 1990 & 0.0 & 0.0 & 0.7 & 7.7 & 22.0 & 32.1 & 53.4 & 58.5 & 24.7 & 16.6 \\
\hline
\end{tabular}

per 100,000 population standardized by European population

${ }^{*}$ Malmö, Sweden age category; 0-44, 45-54, 55-64, 65-74, 75-84, 85

${ }^{\dagger}$ Frederiskberg, Denmark age category; 0-54, 55-64, 65-74, 75-84, 85

${ }^{1)}$ Kiyohara et al. 1988; ${ }^{2}$ Tanaka et al. 1981; ${ }^{3)}$ Inagawa et al. 1988; ${ }^{4)}$ Giroud et al. 1991; ${ }^{5)}$ Jerntorp and Berglund. 1992; ${ }^{6)} \mathrm{J} \phi$ genson et al. 1992

that in Hisayama (Kiyohara et al. 1988), a rural area.

It might be possible that some cases of $\mathrm{SAH}$, who were dead on arrival at local hospitals, had been eliminated from this study. It may be necessary to elucidate the number of such cases to clarify the accurate incidence of SAH in future. The higher incidence of SAH in Hisayama (Kiyohara et al. 1988), can partly be explained by high performance rate of autopsy $(81.4 \%)$ in the cohort subject. In addition, epidemiological studies to clarify the factors underlying regional differences in the incidences of SAH should be studied. 


\section{References}

1) Giroud, M., Milan, C., Beuriat, P., Gras, P., Essayagh, E., Arveux, P. \& Dumas, R. (1991) Incidence and survival rates during a two-year period of intracerebral and subarachnoid hemorrhages, cortical infarcts, lacunes and transient registry of Dijon: 1985-1989. Int. J. Epidemiol., 20, 893-899.

2) Inagawa, T., Ishikawa, S., Aoki, H., Takahashi, M. \& Yoshimoto, H. (1988) Aneurysmal subarachnoid hemorrhage in Izumo City and Shimane Prefecture of Japan Incidence. Stroke, 19, 170-175.

3) Jerntorp, P. \& Berglund, G. (1992) Stroke registry in Malmö Sweden. Stroke, 23, 357-361.

4) J $\varnothing$ gensen, H., Plesner, A., Hubbe, P. \& Larsen, K. (1992) Marked increase of stroke incidence in men between 1972 and 1990 in Frederiksberg, Denmark. Stroke, 23, 1701-1705.

5) Kiyohara, Y., Ueda, K., Hasuo, Y., Wada, J., Kawano, H., Kato, I., Sinkawa, A., Ohmura, T., Iwamoto, H., Omae, T. \& Fujishima, M. (1989) Incidence and prognosis of subarachnoid hemorrhage in a Japanese rural community. Stroke, 20, 11501155.

6) Tanaka, H., Ueda, Y., Date, C., Baba, T., Yamashita, H., Hayashi, M., Shoji, H., Owada, K., Baba, K., Shibuya, M., Kon, T. \& Detels, R. (1981) Incidence of stroke in Shibata, Japan: 1976-1978. Stroke, 12, 460-466.

7) World Health Organization (1994) World Health Statistics Annual 1993, Geneva. 